\title{
Design of the rubrics evaluation lists and the education contents for improve the computational thinking by using physical computing tool
}

\author{
Junhyeong Lee ${ }^{1}$ and Hyeongok Lee ${ }^{2 *}$ \\ Research Scholar, Department of Computer Education, Sunchon National University, Republic of Korea ${ }^{1}$ \\ Associate Professor, Department of Computer Education, Sunchon National University, Republic of Korea ${ }^{2}$
}

Received: 21-June-2018; Revised: 25-August-2018; Accepted: 2-November-2018

(C)2019 Junhyeong Lee and Hyeongok Lee. Published by ACCENT Social and Welfare Society. This is an open access article distributed under the Creative Commons Attribution (CC BY) License, which permits unrestricted use, distribution, and reproduction in any medium, provided the original work is properly cited.

\begin{abstract}
The purpose of this study is to design education program and computational thinking (CT) rubrics evaluation lists using physical computing tools to improve effective CT skills. To do this, we analyzed the elements of CT, rubrics evaluation lists, and physical computing tools, and presented 12 rubric evaluation lists for learners. The contents of the education program were designed based on the real-life problem solving (RPLS) model. The education program design set a one topic for artifacts to be consistent with are CT element. Based on the rubrics of Kim JK, designed by analyzing the CT framework, we devised a CT rubrics evaluation list used the physical computing tools. After, this study is expected to be used as an effective CT teach program using the physical computing tools through the verification of the empirical results.
\end{abstract}

Keywords

Computational thinking, Physical computing, Rubrics, CT-RLPS.

\section{Introduction}

Starting from the science technology engineering mathematics (STEM) education from the national science foundation in USA. Arts added, STEAM education has become a major educational goal of each country. STEAM education means a convergence education for educating talented students. Therefore, as the fourth industrial revolution of industry approaches, the world is hastening to prepare about STEAM education. Currently, computer software (SW) education is emphasized as a stem of STEAM education. The reason is that $\mathrm{SW}$ education itself is associated with the fostering of convergence talents required by STEAM. In 2006 Wing JM, presented the concept of computational thinking (CT) [1]. It is not like training of computer science engineer, people should have logical and analytical thinking skills like the computer scientists. In the fourth revolution of industry, the ability to read and interpret digital media and produce new digital contents is the basic skill of a new social member [2].

\footnotetext{
*Author for correspondence
}

In this context, SW education can get various educational effects by learning problem-solving ability, logic, structuralization, and computer literacy that is the basis of future SW technology.

For this reason, K-12, a regular education program in the United States, is making computer science education compulsory and programming education was compulsory in the Denmark, Australia and France [3]. In the republic of Korea, the revised information \& computer education course was announced in 2015 and the information \& computer curriculum for middle schools was compulsory in 2018. However, it is not easy to evaluate the abstractedness because CT education which is the main purpose of the SW education is the thinking skills. Therefore, research on CT learning is actively being carried out in order to present the direction of SW education evaluation. Current research on CT evaluated was being developed focused on the use of scratch, an educational programming language. There are not many CT education research on physical computing tools that enhance student interest and learning effectiveness. The reason of difficulty to design of teaching methods in detail for CT on physical computing is that it has the widest range of 
physical computing tools and the definition of physical computing tools for CT education is unclear. In CT education, it is generally forced on Arduino, one of the educational tools of physical computing tools. Therefore, for the improving the effectiveness of SW education, CT education program using physical computing tools based on CT training model and framework is needed. This research is analyzed using physical computing tools to make effective education for CT ability improvement. And plan to design a CT training program using physical computing tools based on the $\mathrm{CT}$ rubric evaluation list and CT education model. Therefore, in order to enhance the effectiveness of SW education, CT education program using physical computing tools based on the CT framework teaching model is needed. The purpose of this study is to analyze the physical computing tools and CT elements for effective to improve CT competence.

Table 1 CT framework of Brennan and Resnick

\begin{tabular}{|c|c|c|}
\hline Computational concepts & Computational practices & Computational perspectives \\
\hline -Sequences & -Being incremental and iterative & -Expressing \\
\hline •Loops & -Testing and debugging & -Connecting \\
\hline •Parallelism & -Reusing and remixing & -Questioning \\
\hline •Events & -Abstracting and modularizing & \\
\hline \multicolumn{3}{|l|}{-Algorithms \& procedures } \\
\hline \multicolumn{3}{|l|}{-Conditionals } \\
\hline \multicolumn{3}{|l|}{-Operators } \\
\hline -Data & & \\
\hline
\end{tabular}

Bort \& Brylow [5] presented a Rubric for measuring CT. The ten basic CT elements of the Computer Science Teachers Association (CSTA) presented in Table 2 were evaluated on three scales. CSTA of the United States, International Society for Technology in Education (ISTE), and the College Board (CB) and
For this purpose, it is based on both the rubrics list and selected CT education models. We plan to design a CT education program used physical computing tools. In this study, we analyzed the CT element and rubric evaluation in the following order. First, the CT elements are analyzed and defined. Second, we select a physical computing tools suitable for CT education. Third, analyze rubrics evaluation lists for CT education. Fourth, we will design new rubrics evaluation lists using physical computing tools by applying physical computing tools and rubrics evaluation lists. Fifth, we will design to the CT education program based on new CT rubric evaluation.

\section{Theoretical background}

2.1CT elements and rubrics evaluation

About CT elements, Brennan and Resnick [4] have developed a CT evaluation framework as shown in Table 1.

Table 2 Elements of CT

\begin{tabular}{|c|c|}
\hline \multicolumn{2}{|c|}{ CSTA \& ISTE } \\
\hline -Data collection & -Automation \\
\hline -Data analysis & -Algorithm \& procedures \\
\hline -Data representation & -Simulation \\
\hline -Problem decomposition & •Paralleization \\
\hline -Abstractions & -Connection to order fields \\
\hline \multicolumn{2}{|c|}{ CB \& NSF } \\
\hline -Connecting computer & -Analyzing problems and artifacts \\
\hline •Creating computer & •Communicating \\
\hline -Artifacts & -Collaborating \\
\hline -Abstractions & \\
\hline \multicolumn{2}{|c|}{ Selby\& Wollard } \\
\hline -Algorithmic thinking & -Generalization \\
\hline -Decomposition & •Abstractions \\
\hline & •Evaluation \\
\hline
\end{tabular}


Then in 2017, Kim JK, based on the learning objectives of computational thinking practices in the AP computer science principles curriculum framework of $\mathrm{CB}$. He proposed improved rubric evaluations through abstraction and configuration classification of artifacts [6].

As a result of the research about Table 3, it was confirmed that we obtained the ability to solve the computing problem through the proposed Rubric evaluation item. In this research, learners showed errors in data conversion in Table $3 \mathrm{P} 1$. The conversion of a data type from a computer differs from the unit that the computer handles according that we routine to the integers and decimal fraction. It is a common error of a novice programmer.

We confirmed that there is an error in the final output, in the process of integrating and verifying the modules in the collaborative process of Table $3 \mathrm{P} 4$. This is because the names of variables and functions used by learners are different from the integrated part of the result. It is necessary to supplement the theoretical lessons to the integration of the outputs and testing.

Table 3 Kim JK (2017), proposed rubrics evaluation lists

\begin{tabular}{|c|c|c|c|}
\hline CT & Category & Sign & Rubric evaluation lists about CT \\
\hline \multirow[t]{4}{*}{ Abstracting } & Connecting computer & $\mathrm{P} 1$ & $\begin{array}{l}\text { 1.Understanding data representation and transform encoding } \\
\text { techniques } \\
\text { 2.Abstract logical symbol semantics and real-world logic } \\
\text { representation } \\
\text { 3.Understand the types, principles, and necessities of data structures } \\
\text { and operations }\end{array}$ \\
\hline & $\begin{array}{l}\text { Analyzing problems } \\
\text { and artifacts }\end{array}$ & $\mathrm{P} 2$ & $\begin{array}{l}\text { 1.Understanding the types and functions of control flow commands } \\
\text { 2.Divide and represent problems and define and modularize modules } \\
\text { 3.Identify the patterns, logic and skills needed to solve the problem }\end{array}$ \\
\hline & Communicating & P3 & $\begin{array}{l}\text { 1.Understanding abstract symbols to express problem-solving } \\
\text { process }\end{array}$ \\
\hline & Collaborating & $\mathrm{P} 4$ & $\begin{array}{l}\text { 1. Reduce troubleshooting costs for parallel processing and } \\
\text { collaboration }\end{array}$ \\
\hline \multirow[t]{4}{*}{$\begin{array}{l}\text { Artifacts } \\
\text { (Automation) }\end{array}$} & Connecting computer & P1 & $\begin{array}{l}\text { 1.Valid constants and types according to data type } \\
\text { 2.Use Boolean expressions with valid logic and syntax } \\
\text { 3.List and dictionary definition, operation }\end{array}$ \\
\hline & Creating computer artifacts & $\mathrm{P} 2$ & $\begin{array}{l}\text { 1.Control flow using condition and loop } \\
\text { 2.Modular programming using functions and arguments } \\
\text { 3.Creating arithmetic, logic, comparison and regular expressions }\end{array}$ \\
\hline & Communicating & P3 & 1. Reflection of modeling code for problem solving of abstract code \\
\hline & Collaborating & $\mathrm{P} 4$ & Module creation and integration testing through collaboration \\
\hline
\end{tabular}

In addition, structural programming is not smoothly implemented in the modularization part through function definition. These errors can be suggested improved by supplementing teaching and learning methods. Therefore, we made additional chapters on simulation and collaboration.

Using the cronbach's alpha coefficient, J.K. Kim tested reliability was verified in 0.73 and Abstracting for artifacts and 0.8 .

\subsection{Concept of physical computing}

Physical computing, Prof. Dan O 'Sullivan and Prof. Tom Igoe, taught Interactive physical systems in the interactive telecommunications program, a graduate program at New York University, and categorized the technical forms of physical computing into four categories [7].

48
Physical computing expresses that inputting information in a way that senses physical signals such as sound, motion, light, heat and etc. instead of input methods such as a keyboard or a mouse. To do this, physical computing uses a microcontroller to control the digital input, the digital output, the analog input, and the analog output. When any physical input is received from the user, it outputs the result to the user in digital or analog method. Physical computing has the advantage of being able to access digital media in a variety of ways, even for those unfamiliar with computers.

\subsection{Education model for CT education}

Seiter \& Foreman's progression of early computational thinking (PACT) model is often used in domestic evaluation studies. The learner's scratch output was evaluated as evidence variables, design 
pattern variable and computational thinking concepts [8].

In 2016, Sung YH, presented a CT-SPI model to improve the computing thinking ability. To internalize using an Arduino to learner internalize the CT element constructing construct the system thinking, prototyping, and interaction order [9].
In 2017, Lee $\mathrm{CH}$, has developed the computational thinking-based real-life problem solving (CT-RLPS) model for software education [10]. The CT-RLPS model consists of three stages: problem analysis and decomposition, design and implementation. His research is to educate computing thinking by applying sub-elements of each step to real life problems. The contents are shown in Figure 1. In this paper, CT education curriculum that uses physical computing tools, based on CT-RLPS, was designed.

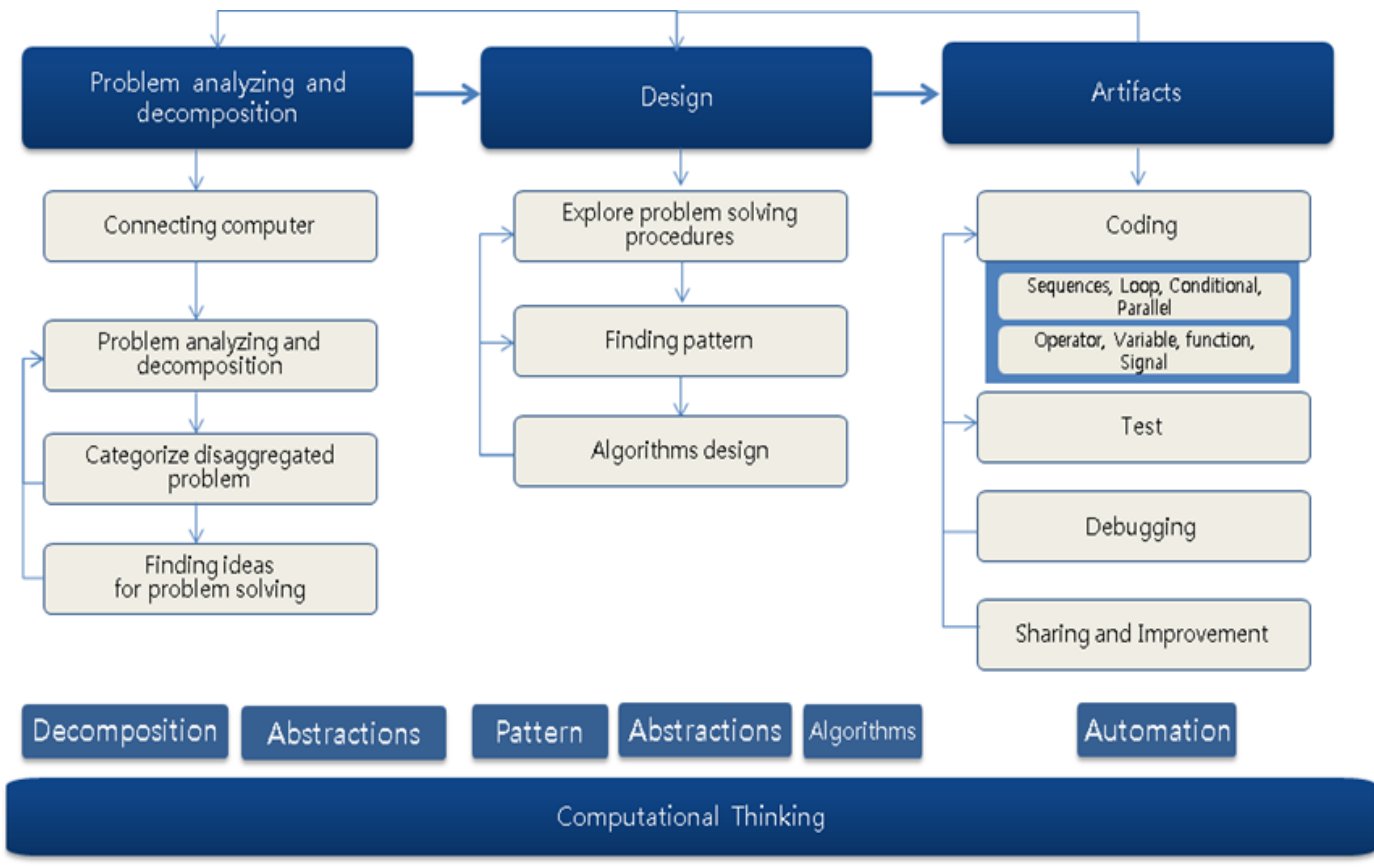

Figure 1 CT-RLPS model

\section{Contents}

3.1CT education elements elicitation: based on rubric evaluation lists uses physical computing tools, for improving $\mathrm{CT}$

For CT education improvement, it is necessary to summarize abstract concepts and express them in physical computing tools to solve problems. The contents are as follows, which is based on the Brennan \& Resnick framework for CT evaluation using physical computing. Then we applied the rubrics suggested elements of Kim JK to reconstruct the existing CT element and set the CT element. The rubrics lists designed were reviewed by three experts. The final rubric was determined through a questionnaire.

1. Must be expressed in the physical computing tools after analyzing in the real world of abstract data.

2. It must be available tools of transforming and expressing data types.
3. To solve the problem, it should be able to understand and written the abstract concept through the tools.

4. For the purpose of parallel processing, it should be able to understand and express the concept of shortening the cost of problem solving, through parallelization in the tools.

Also, for CT enhancement training, the physical computing tools should be able to implement the automatic resolution of the problem and be capable of logical and iterative sequential configuration.

1. Transformation between data and data error correction according to the format of data must be expressed or understandable.

2. Apply correct logic and grammar usage so that the results can be verified in the tools.

3. Should be able to see the results of the operation, according to the data structure using lists, definitions, and operations.

49 
4. Should be able to express the flow of control by using conditions and loops.

5. Should be possible to express and implement modularization using functions.

6 . The solution of the problem should be able to be understood or expressed by the code writing flow and commands, and the modular expression should be possible by dividing the problem. Functions related to problem solving should be able to be expressed in logical order.

7. Automated module and logic, grammar must be running concurrently in parallel.

3.2Select of physical computing tool for CT improving

Arduino, one of the representatives, physical computing tools used in CT education is actively used in CT education because of its advantage that it can be easily programmed without electric and electronic expert knowledge.

However, it has a disadvantage that CT learners take more time in Arduino circuit design and assembly than actual CT learning. Therefore, in order to be effective CT education using physical computing tools, there are studies on diverse physical computing tools. And because of this reason's various companies are developing and education selling tools for CT education. Table 4 shows the physical computing tools based on the Arduino. Corp.Makeblock's m-boot simplifies circuit and wire connections, made in China. The sensor board of the ENTRY education center, which was created for education by adding input/output sensors mainly used in CT training, made in Korea. Based on Arduino, integrated hardware platform named coconut equipped the input and output devices and motors, made by corp. Huintech in Korea.

Based on the Arduino, each company added essential functions to make it easier for learners to learn $\mathrm{CT}$, added circuitry and Bluetooth capabilities so that the learners did not spend unnecessary time on circuit design and data upload / download.

Organizing CT education program using coconut from corp. Huintech which is a robot-type tool with a motor to facilitate instant expression and understanding of modularization and parallelization, which is one of the components of CT.
Table 4 Physical computing tools-based arduino for CT teaching

image

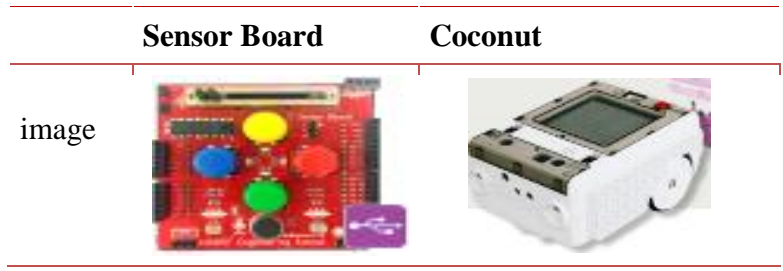

A number of similar physical computing tools have been developed. In a typical computer environment, simple software installation enables immediate CT training. Applications corresponding to tablets or smartphones are also provided. Therefore, learners can make CT learning more interesting, fun and easy.

\section{Result}

The following CT-RPLS model education program was proposed based on the rubric evaluation items based on the CT education elements. The CT curriculum of the activities, education curriculum and the activities, education contents of the secondary information curriculum are composed of simpler sorting tasks and corresponding CT elements among them. There is a need to provide an organic and systematic context flow between the electronics prototyping lab (EPL), the physical computing paradigm, and the algorithm design used for CT learning. The CT components of CSTA \& ISTE are organically thought out for the problems to be solved: data collection, data analysis, data representation, problem decomposition, abstraction, algorithms and procedures, automation, simulation and parallelization. In order to improve the $\mathrm{CT}$, the physical computing utilization education program design is shown in Table 5. The education design should be conducted on a 12-week basis for two hours a week. Do not perform separate artifacts for each chapter. In order to produce one security robot, we have taught for 12 weeks. Each step has an organic relevance for the final output, and finally, each stage feedback is possible and CT learning can be achieved by completing integrated education. 
The CT framework of Brennan \& Resnick presents the conceptual domain of CT and Kim JK proposed rubrics evaluation lists presented the rubric evaluation direction of CT. CT education is a convergent model of education, where problem solving and disassembling, design and abstraction, automation and implementation are linked to each other. The education must be made with connectivity and continuity between CT elements. Therefore, a training program and rubrics evaluation linked to integrated flow using direct the physical computing tool for the CT improves based on the CT-RPLS model is shown in Table 6.

Table 5 Physical computing education program for CT improving

\begin{tabular}{|c|c|c|c|c|}
\hline \multicolumn{2}{|c|}{ Chapter } & \multirow{2}{*}{$\begin{array}{l}\text { Contents } \\
\text { Physical computing and CT basic }\end{array}$} & \multirow{2}{*}{$\begin{array}{l}\text { CT Elements } \\
-\end{array}$} & \multirow{5}{*}{$\begin{array}{l}\text { CT- } \\
\text { RLPS } \\
\text { Problem } \\
\text { analysis and } \\
\text { decomposition }\end{array}$} \\
\hline 1 & Basic & & & \\
\hline 2 & Connecting computer & Development of security robot & Data collection & \\
\hline 3 & Data analysis & Understand differences in representation by data type & Data analysis & \\
\hline 4 & Problem decomposition & $\begin{array}{l}\text { Problem resolution } 1 \text {. Obstacle detection 2. LED } 3 \\
\text { Sound }\end{array}$ & $\begin{array}{l}\text { Problem } \\
\text { decomposition }\end{array}$ & \\
\hline 5 & Problems abstractions & Configure action for problems solving & Abstractions & \multirow[t]{3}{*}{ Design } \\
\hline 6 & Expressing of data & LED change according to sound & Data presentation & \\
\hline 7 & Problems parallelization & Parallel configure action for problems solving & Parallelization & \\
\hline 8 & $\begin{array}{l}\text { Problems solving } \\
\text { sequences }\end{array}$ & lists and sequence structures creating & $\begin{array}{l}\text { Algorithms\& } \\
\text { procedures }\end{array}$ & \multirow[t]{5}{*}{$\begin{array}{l}\text { Creating } \\
\text { artifacts }\end{array}$} \\
\hline 9 & $\begin{array}{l}\text { Conditionals and loops } \\
\text { control }\end{array}$ & Operation set when obstacle is detected & $\begin{array}{l}\text { Algorithms \& } \\
\text { procedures }\end{array}$ & \\
\hline 10 & $\begin{array}{l}\text { Functions and } \\
\text { modularization }\end{array}$ & $\begin{array}{l}\text { Security robot action function creation and } \\
\text { modularization }\end{array}$ & Automation & \\
\hline 11 & Artifacts test & $\begin{array}{l}\text { Determine the logic of abstraction is correctly } \\
\text { represented. }\end{array}$ & Simulation & \\
\hline 12 & $\begin{array}{l}\text { Creating an integration } \\
\text { module }\end{array}$ & Each function are operated parallel action & $\begin{array}{l}\text { Parallelization } \\
\text { simulation }\end{array}$ & \\
\hline
\end{tabular}

Table 6 Evaluation rubric items for CT: used physical computing tools

\begin{tabular}{|c|c|c|}
\hline & & Evaluation list \\
\hline 1 & Basic & - \\
\hline 2 & $\begin{array}{l}\text { Connecting } \\
\text { computer }\end{array}$ & Ability to collect real-life data elements for application to physical computing tools \\
\hline 3 & Data analysis & $\begin{array}{l}\text { Possible to real-life data that can be handled by physical computing tools can be classified by data } \\
\text { type }\end{array}$ \\
\hline 4 & $\begin{array}{l}\text { Problem } \\
\text { decomposition }\end{array}$ & $\begin{array}{l}\text { Ability to decomposition: the problems can be into logical units form solving. The procedure to be } \\
\text { decomposition step by step }\end{array}$ \\
\hline 5 & $\begin{array}{l}\text { Problems } \\
\text { abstractions }\end{array}$ & $\begin{array}{l}\text { The problem expressing to solving, and understanding about the principles of modularized } \\
\text { partitioning }\end{array}$ \\
\hline 6 & Expressing of data & $\begin{array}{l}\text { Whether data can be represented and transformed using variables or lists in physical computing } \\
\text { parish }\end{array}$ \\
\hline 7 & $\begin{array}{l}\text { Problems } \\
\text { parallelization }\end{array}$ & $\begin{array}{l}\text { Simultaneous processing is performed between the operating structures of physical computing tool, } \\
\text { and synchronization is achieved through exchange of messages between objects }\end{array}$ \\
\hline 8 & $\begin{array}{l}\text { Problems solving } \\
\text { sequences }\end{array}$ & $\begin{array}{l}\text { Whether code of correct logic that can be expressed in physical computing tool: initialization, } \\
\text { implementation of variable }\end{array}$ \\
\hline 9 & $\begin{array}{l}\text { Conditionals and } \\
\text { loops control }\end{array}$ & $\begin{array}{l}\text { Whether the correct logic conditions, arithmetic, comparison equations, functions, and control flow } \\
\text { to implement for problem solving behavior in physical computing tool }\end{array}$ \\
\hline 10 & $\begin{array}{l}\text { Functions and } \\
\text { modularization }\end{array}$ & Whether the can write about repetitive automation through physical computing tool \\
\hline 11 & Artifacts test & $\begin{array}{l}\text { Possible to check the operation result according to the data(parameter) possible through physical } \\
\text { computing tool }\end{array}$ \\
\hline 12 & $\begin{array}{l}\text { Creating an } \\
\text { integration module }\end{array}$ & Whether the integration between functions and modules \\
\hline
\end{tabular}




\section{Conclusion}

Following this paper to explore rubrics evaluation items for CT improvement based on the CT elements and CT framework. Through the CT-RLPS model CT education program which has used physical computing tool was suggested. This will allow CT learners to learn the components of CT and logical thinking systematically. The rubric evaluation lists and the educate design were designed for effective SW coding teach and CT leaner. This paper has limitations that must be applied and verified in actual schools. However, CT training should not be limited to the artifacts of irrelevant of CT learning and the acquisition of basic programming skills. I hope that it will help me to acquire more sophisticated and gradual CT skills.

\section{Acknowledgment}

None.

\section{Conflicts of interest}

The authors have no conflicts of interest to declare.

\section{References}

[1] Wing JM. Computational thinking. Communications of the ACM. 2006; 49(3):33-5.

[2] Pérez-Escoda A, Rodríguez-Conde MJ. Digital literacy and digital competences in the educational evaluation: USA and IEA contexts. In proceedings of the international conference on technological ecosystems for enhancing multiculturality 2015 (pp. 355-60). ACM.

[3] Computational Thinking in K-12 Education: teacher resources. Second edition; 2011. http://www.iste.org/docs/ct-documents/ct-teacherresources_2ed-pdf.pdf. Accessed 12 April 2018.

[4] Brennan K, Resnick M. New frameworks for studying and assessing the development of computational thinking. In proceedings of the annual meeting of the American educational research association, Vancouver, Canada 2012 (pp. 1-25).
[5] Bort H, Brylow D. CS4impact: measuring computational thinking concepts present in CS4HS participant lesson plans. In proceeding of the technical symposium on computer science education 2013 (pp. 427-32). ACM.

[6] Kim JK, Development of rubric for assessing computational thinking concepts and programming ability. The Korean Association of Computer Education. 2017; 20(6):27-36.

[7] O'Sullivan D, Igoe T. Physical computing: sensing and controlling the physical world with computers. Boston, MA, USA: Thomson; 2004.

[8] Seiter L, Foreman B. Modeling the learning progressions of computational thinking of primary grade students. In proceedings of the international conference on international computing education research 2013 (pp. 59-66). ACM.

[9] Sung YH. Development and application of CT-SPI model for improving computational thinking for elementary school students. Journal of the Korea Society of Computer and Information. 2016; 21(1):169-80.

[10] Lee, Cheol-Hyun. Computational thinking-based reallife problem solving (CT-RLPS) model development for software education. Journal of Korean Practical Arts Education. 2017; 30(3): 33-57.

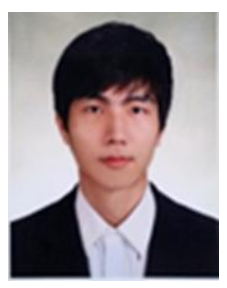

JunHyeong Lee received his M.Sc. degree in Department of Computer Education Information Science from the Sunchon National University in Republic of Korea. His research interests are in Computer Education, Computational Thinking, Physical Computing and Software Education.

Email: jhlee5336@scnu.ac.kr

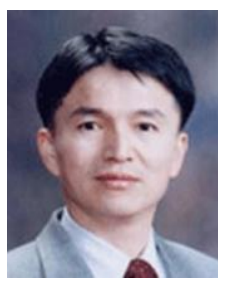

Hyeongok Lee received his Ph.D degree in computer science from Chonnam National University in Korea. $\mathrm{He}$ is an Associate Professor, Department of Computer Education, Sunchon National University in Republic of Korea from 2002 to present. His research interests include Graph Theory, Design and Analysis of Algorithm, Interconnection Network and Computer Education.

Email: oklee@scnu.ac.kr 